UCRL-JC-121416

PREPRINT

$$
\text { CONE-9505238--5 }
$$

\title{
MPC\&A for Plutonium Disposition in the Russian Federation
}

W. G. Sutcliffe

This paper was prepared for submittal to the North Atlantic Treaty Organization Advanced Research Workshop

St. Petersburg, Russia

May 16, 1995

August 8, 1995

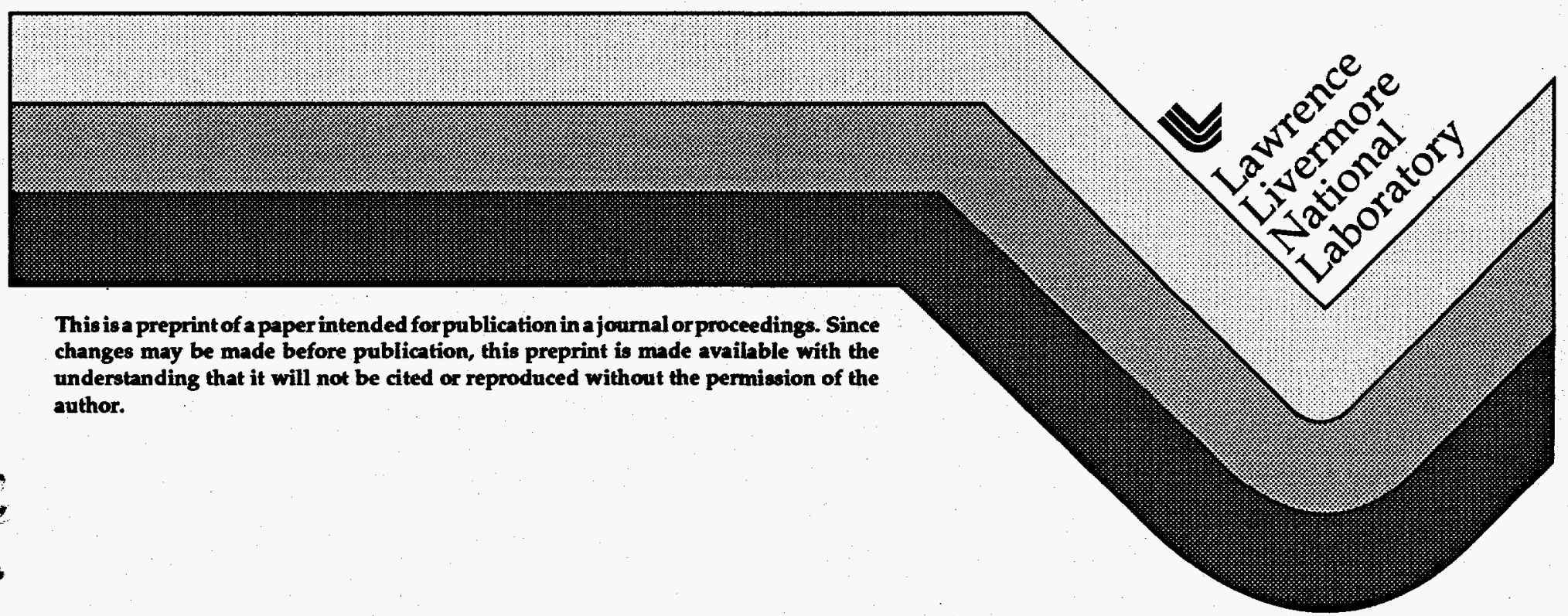

DISTRIBUTION OF THIS DOCUMENT IS UNIMITED

DISTRIBUTION OF THIS DOCUMENT IS INIMITET

DISTRIBUTION OF THIS DOCUMENT IS INNMITITD 


\section{'DISCLAIMER}

This document was prepared as an account of work sponsored by an agency of the United States Government. Neither the United States Government nor the University of California nor any of their employees, makes any warranty, express or implied, or assumes any legal liability or responsibility for the accuracy, completeness, or usefulness of any information, apparatus, product, or process disclosed, or represents that its use would not infringe privately owned rights. Reference herein to any specific commercial products, process, or service by trade name, trademark, manufacturer, or otherwise, does not necessarily constitute or imply its endorsement, recommendation, or favoring by the United States Government or the University of California. The views and opinions of authors expressed herein do not necessarily state or reflect those of the United States Government or the University of California, and shall not be used for advertising or product endorsement purposes. 


\section{DISCLAMMER}

Portions of this document may be illegible in electronic image products. Images are produced from the best available original document. 


\section{MPC\&A for Plutonium Disposition in the Russian Federation}

W. G. Sutcliffe

Center for Security and Technology Studies

Lawrence Livermore National Laboratory

NATO Advanced Research Workshop:

"Disposal of Weapons Plutonium-Approaches and Prospects"

St. Petersburg, Russia

May 16, 1995

Disclaimer

The views expressed in this paper are those of the author and should not be taken to reflect positions of Lawrence Livermore National Laboratory, the University of California, the Department of Energy, or the U.S. Government.

\section{Introduction}

The issue of what to do with excess fissile materials from dismantled nuclear weapons has been discussed for a number of years. ${ }^{1}$ The options or alternatives commanding the most attention were identified by the American National Academy of Sciences. ${ }^{2}$ For plutonium these options are: (1) the fabrication and use of mixed-oxide (MOX) reactor fuel followed by the disposal of the spent fuel, or

1 W. G. Sutcliffe, Ed., Fissile Materials from Nuclear Arms Reductions: A Question of Disposition, Lawrence Livermore National Laboratory, Livermore, CA, CONF-910208 (February 1991).

2 Committee on International Security and Arms Control, National Academy of Sciences, Management and Disposition of Excess Weapons Plutonium (National Academy Press, Washington, DC, 1994). 
(2) vitrification (immobilization) of plutonium combined with highly radioactive material followed by direct disposal. The Academy report also identified the alternative of disposal in a deep borehole as requiring further study before being eliminated or accepted. The report emphasized security of nuclear materials as a principal factor in considering management and disposition decisions. Security of materials is particularly important in the near term-now-long before ultimate disposition can be accomplished.

The MOX option was the subject of a NATO workshop held at Obninsk, Russia in October $1994 .^{3}$ Hence this paper does not deal with the MOX alternative in detail. It deals with the following: materials protection, control, and accounting (MPC\&A) for immobilization and disposal; the immobilization vs MOX alternatives; the security of disposed plutonium; the need to demonstrate MPC\&A for plutonium disposition; and, finally, a recommended investment to quickly and inexpensively improve the protection of fissile materials in Russia. It is the author's view that near-term management is of overriding importance. That is, with respect to the ultimate disposition of excess nuclear materials, how we get there is more important than where we are going.

\section{MPC\&A for Immobilization and Disposal}

Materials protection, control, and accounting (MPC\&A) measures for plutonium are necessary whether the plutonium is embedded in reactor fuel or in glass, ceramic, or other material. Existing MPC\&A practices for mixed oxide (MOX) reactor fuel containing plutonium can provide a basis for the establishment of MPC\&A for direct immobilization without any unusual difficulties.

In the MOX option, the plutonium passes through a number of stages or processes. These include recovery of the plutonium from weapons components, conversion to oxide, fabrication into reactor fuel, exposure in a reactor, storage of spent fuel, and geologic disposal of spent fuel (or reprocessing and disposal of high-level waste). For direct immobilization and disposal the sequence is similar, except that the processes 
that correspond to fuel fabrication and reactor exposure are combined in the immobilization step, in which waste forms (e.g., glass logs) are formed with embedded fission products or high-level waste. For both the MOX and immobilization options, a number of transportation and interim storage (staging) steps will be required. See Fig. 1.

- Once through MOX Option

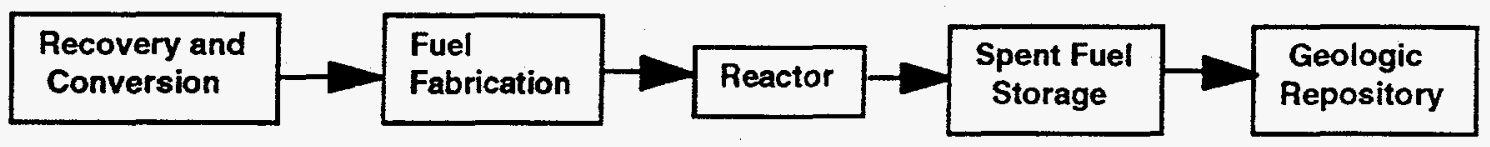

- Immobilization Option

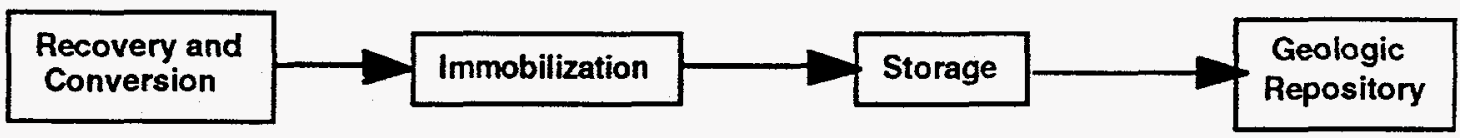

Figure 1 PU DISPOSTION PROCESSES

MPC\&A is most crucial before the plutonium is combined with radioactive materials, especially when the plutonium is in bulk form. Standard MPC\&A methods used in Europe and Japan to protect and safeguard the transportation and storage of plutonium, MOX fuel fabrication facilities, and reprocessing facilities could be adapted for use in a facility that immobilizes plutonium mixed with highly-radioactive material.

Inventorying acts with other measures to provide for the security of the plutonium. It also provides important assurance that criticality-based limits for the immobilization processing and repository emplacement are met. For security, it is only necessary to ensure that all items (containers) are accounted for and have not been tampered with. Directly inventorying the amount of plutonium immobilized with fission products or high-level waste is not necessary. Methods used for MC\&A of plutonium without fission products could be adapted for this purpose. Tags on the containers can facilitate inventorying, which could be done remotely, possibly with the use of robots. Seals or continuous surveillance could ensure that no material has been removed. Visual surveillance using television and/or a 
combination of weight, motion, and radiation sensors could be used to detect removal of material or tampering with containers.

Periodic inventories of containers would be required in any storage facility and in a mined geologic repository until the repository was sealed. Inventorying would likely be supplemented by containment and surveillance methods such as portalperimeter monitoring. Sensors might include motion and seismic sensors on the perimeter and gamma and neutron radiation detectors at the portals. Inventorying plutonium disposed of in a deep borehole is not practical.

\section{Immobilization vs MOX}

A number of criteria have been put forth for the decision of whether to choose a MOX or an immobilization option for the disposition of excess weapons plutonium. ${ }^{4}$ In particular, considerable attention has been given to economic criteria such as net cost. ${ }^{5}$ However, the National Academy of Sciences' committee noted that economics should not be the primary criterion driving the decision. This is because the national security benefit from the safe, secure disposition of plutonium is large, and the cost for such disposition is considerably smaller than the budget for national security. The disposition cost (for a nominal 50 tonnes of plutonium) is expected to be a few billion dollars over several years, which is the order of $1 \%$ of what the United States spends for national security each year.

As discussed in the previous section, required MPC\&A would likely be comparable for MOX and immobilization options. Immobilization could have an advantage of

4 Committee on International Security and Arms Control, National Academy of Sciences, Management and Disposition of Excess Weapons Plutonium (National Academy Press, Washington, DC, 1994). See also U.S. Department of Energy, Office of Fissile Materials Disposition, Long-Term Storage and Disposition of Weapons-Usable Fissile Materials Programmatic Environmental Impact Statement, Implementation Plan, March 1995.

5 Specific cost estimates for the reactor and vitrification options can be found in Management and Disposition of Excess Weapons Plutonium: Report of the Panel on Reactor-Related Options (National Academy Press, Washington, DC, July 1995). The U.S. Department of Energy has also concluded a study of reactor options that analyzes costs: Plutonium Disposition Study, Phase II (to be published). 
less storage (staging) and transportation because of fewer distinct operations. That is, the addition of radioactive material may be combined with immobilization (vitrification) in one facility. The disadvantage is that there is no operational experience for MPC\&A measures for these new processes.

In Russia it is argued that not only is MOX a more economical option, it utilizes a valued resource. Rather than discuss these somewhat contentious arguments, we will argue for another important criterion that discriminates between the choices in Russia.

Perhaps the most important criteria for disposition are those collectively called proliferation resistance. They deal with making materials less attractive and/or less available for use in weapons. One measure of the exposure of the material to possible theft or reuse is the time until the start of implementation of the disposition decision. It has been said that weapons plutonium (and unsafeguarded civil plutonium) represents "a clear and present danger." Starting (or even finishing) the disposition of excess material will not completely remove this danger because Russia (and the United States) will retain significant stockpiles of nuclear weapons and materials for some time to come, and more material can be expected to be declared excess as time goes on. However, there is great value in making the decision and starting the disposition program as soon as possible. Such action will generate a programmatic momentum toward controlling, processing, and disposing of excess nuclear materials, and as such could bolster progress toward a more comprehensive regime to protect and safeguard all nuclear materials. In any case, an early decision, accompanied by the identification of the initial "excess" material (e.g., the first 10 tonnes) would focus attention and provide a specific target for assistance.

It is important that this programmatic momentum be established while conditions in Russia and the United States are favorable. Economic and political conditions in Russia make the future somewhat uncertain. Impatience in the United States could eventually reduce support for the disposition program, particularly in Russia. The United States has declared that excess material will be placed under IAEA safeguards; a similar declaration from Russia would be welcomed.

The reasons that a MOX decision could be implemented sooner than an immobilization and disposal decision in Russia are twofold. The first is 
institutional. In Russia, the majority opinion, especially espoused by MINATOM, is that MOX is the preferred option. This is undoubtedly connected to the desire to benefit from previous expenditures by reaping the intrinsic energy value in plutonium. (In the United States there is no such clear majority of opinion.) The second reason is that vitrification of plutonium would require more $R \& D$ than the MOX option; and there may be less infrastructure to support vitrification or immobilization than MOX. In particular, it has been reported that currently there may not be enough high-level waste available to provide an adequate radiation barrier if all excess plutonium is vitrified. ${ }^{6}$

Another factor may be that an immobilization option in Russia is more closely tied to the development of a geologic repository than is a MOX option; and the technical, institutional, and political processes required to develop a repository in Russia are not fully developed. Throughout the world, long-term surface storage of spent fuel is, by necessity, becoming more accepted; and dry storage for aged (cooled) spent fuel is being increasingly utilized. Even if a once-through MOX cycle is adopted, Russia may decide not to dispose of spent fuel in a repository, in order to preserve a future reprocessing option.

MINATOM prefers the option to use weapons plutonium in fast BN-type liquid metal reactors, arguing that this technology results in reduced amounts and toxicity of waste. However, it appears that the Russians cannot afford to build BN reactors, and the rest of the world is unlikely to fund such development. Burning MOX in light water reactors, on the other hand, appears to be acceptable, as indicated at the NATO meeting last October in Obninsk. ${ }^{7}$ The West may provide some funding in this case, which is consistent with Russia's desire to exploit plutonium's intrinsic energy value.

Whether plutonium is slated for MOX or direct disposal, it will have to be recovered from weapons components and (most likely) converted into oxide. The requirements for the oxide, however, might differ depending on whether it will be

6 Foreign Broadcast Information Service, JPRS Report. Arms Control \& Proliferation Issues, Special Edition: Plutonium in Russia: Ecology, Economic, Policy, JPRS-TAC-95-005-L, 2 February 1995.

7 E. R. Merz, C. E. Walter, and G. M. Pshakin, Eds., Mixed Oxide Fuel (MOX) Exploitation and Destruction in Power Reactors," NATO ASI Series (Kluwer Academic Publishers, Dordrecht/Boston/London, 1995). 
an ingredient of MOX or will be immobilized in a glass log or other matrix. Although MOX might be able to tolerate the expected impurities (Am and $\mathrm{Ga}$ ) the grain size and structure could be crucial. Thus the decision on whether or not to pursue the MOX option should be made early so that planning and implementing the metal-to-oxide conversion process can be initiated as early as possible.

Although there are a number of differences between the MOX and immobilization options (for example, MOX use changes the isotopic composition of the plutonium) none of these differences appears compelling, except that the MOX option could start the disposition process significantly sooner. Doing that could be critically important in establishing a programmatic momentum towards a regime of enhanced protection and safeguards for nuclear materials.

\section{Security of Disposed Plutonium}

As with plutonium embedded in spent fuel (which is a percent or less for LWR spent fuel, a few percent for MOX spent fuel), the security of disposed plutonium rests on various characteristics (barriers) of the disposal system. The most important barrier may be the radiation barrier, achieved by the addition of radioactive materials that effectively preclude human contact with the plutonium. The addition of high-level waste or cesium-137 to plutonium immobilized in glass or other material has been proposed to make it as inaccessible as plutonium in spent fuel. This concept of inaccessibility was termed the "spent fuel standard" by the U.S. National Academy of Sciences in their report on the management and disposition of plutonium. ${ }^{8}$ If the radiation barrier is absent, other barriers will have to be considerably augmented to achieve the same level of protection.

The "self protecting" standard for spent fuel is often taken to be $100 \mathrm{rad} / \mathrm{hr}$ (1 gray $/ \mathrm{hr}$ ) at $1 \mathrm{~m}$. Depending on the physical security measures, this may not provide sufficient protection for either spent fuel or immobilized plutonium. It takes an exposure of about 450 rad for a lethal dose (LD50, a 50\% chance of death). In the absence of guards or other measures, one can imagine a scenario in which spent fuel

8 Committee on International Security and Arms Control, National Academy of Sciences, Management and Disposition of Excess Weapons Plutonium (National Academy Press, Washington, DC, 1994). 
or immobilized plutonium is not self-protecting. The dose rate $1 \mathrm{~m}$ from the ends of a spent fuel assembly are reduced by a factor of 5 to 10 from those $1 \mathrm{~m}$ from the midpoint. The dose rate at $5 \mathrm{~m}$ from the midpoint is reduced by over an order of magnitude from that at $1 \mathrm{~m} .9$ Similar reductions with distance and angle can be expected for glass logs containing fission products. ${ }^{i 0}$ To be truly self-protecting (i.e., secure in the absence of other barriers), dose rates should be more than $1000 \mathrm{rad} / \mathrm{hr}$. Fission products, such as ${ }^{137} \mathrm{Cs}$, which provide the barrier have a half life of about 30 years, after which other barriers will have to be augmented. It is possible that the plutonium could be sealed in an geologic repository in that time, replacing the radiation barrier by lack of accessibility, i.e., an isolation barrier.

Chemical dilution alone is not a practical barrier, because chemical separation methods for plutonium are well known ${ }^{11}$ and practiced in many places around the world. Before (and after) immobilization, plutonium must be diluted to less than about $20 \%$ to preclude use as a weapon. Coupled with the radiation barrier, dilution is more effective because chemical separation becomes more difficult (dangerous), costly, and visible.

The immobilization material will likely contain a low percentage of the plutonium because of performance and criticality considerations in a repository or borehole. A low percentage or density of plutonium also means that more packages would have to be stolen or diverted to obtain a given amount of plutonium.

Physical size and weight can be a significant impediment to the theft or diversion of packages containing immobilized plutonium. Fabrication, transportation, and criticality considerations will dictate a maximum size and weight. The minimum size and weight should be set so that equipment such as cranes and forklifts are

9 W. R. Lloyd, M. K. Sheaffer, W. G. Sutcliffe, Dose Rate Estimates from Irradiated Light-Water-Reactor Fuel Assemblies in Air, Lawrence Livermore National Laboratory, Livermore, CA, UCRL-ID-115199 (January 31, 1994).

10 L. J. Jardine, G. A. Armantrout, and L. F. Collins, Utilization of Cs 137 to Generate a Radiation Barrier for Weapons Grade Plutonium Immobilized in Borosilicate Glass Canisters, Lawrence Livermore National Laboratory, Livermore, CA, UCRL-JC-118741, Rev. 1 (January 1995).

11 O. J. Wick, Ed., Plutonium Handbook, A Guide to the Technology, Vols. I \& II (American Nuclear Society, LaGrange Park, IL, 1980). 
necessary to move the packages. That is, they should not be transportable by a few, or even several, individuals. Glass logs being considered are about $0.6 \mathrm{~m}$ in diameter, $3 \mathrm{~m}$ long and weigh about 2 tonnes. Although longer, spent fuel assemblies are smaller and weigh considerably less ( 300 to $600 \mathrm{~kg}$ ). When coupled with the radiation barrier and with physical protection measures such as guards and fences, size and weight are important impediments.

The security of plutonium in a geologic repository or borehole depends on effective, and often synergistic, performance of the barriers designed into the disposal system. If immobilized plutonium is not provided with a radiation barrier, other barriers will have to be significantly enhanced. Currently, theft, rather than covert diversion by the host country, is the primary threat. As well as considering the on-site guards as a response to this threat, the design and evaluation of a security system should include consideration of available backup forces, such as off-duty guards, local and regional police, and nearby military forces. If these "extra".forces are not available, then additional guards and physical protection measures and devices will be required on the site to reduce the risk of theft and provide sufficient security. Analyses (including time and motion studies and conflict simulation) of threat scenarios can help determine the appropriate trade-offs and level of security.

\section{Demonstrating MPC\&A for Plutonium Disposition in Russia}

In a previous paper 12 the need for "monitoring" was discussed as referring to activities designed to assure the international community that nuclear materials are secure and not subject to unauthorized use. There is still widespread apprehension that some materials in Russia are vulnerable to theft and black market trafficking. Officials in Russia have taken this vulnerability seriously and have moved to increase security. ${ }^{13}$ Through various programs, the United States and other

12 W. G. Sutcliffe, A Perspective on Safeguarding and Monitoring Excess Military Plutonium, NATO Advanced Research Workshop: "Mixed Oxide Fuel (MOX) Exploitation and Destruction in Power Reactors," Obninsk, Russia, October 17, 1994.

13 Margaret Shapiro, Russia Orders Tightened Security to Protect Nuclear Materials, The Washington Post, February 24, 1995. 
countries are working with Russia to enhance the security of nuclear materials. ${ }^{14}$ The primary assistance has been in the MPC\&A area. ${ }^{15}$ Although the work on enhancing MPC\&A in Russia has not been secret, it has not been transparent enough to satisfy the world community that Russia has indeed made a long-term commitment to bring MPC\&A in Russia up to world standards, such as those promulgated by the IAEA or EURATOM. Plutonium disposition offers an excellent opportunity for Russia to implement and demonstrate world-class MPC\&A. In particular, any new or modified fuel fabrication, vitrification, or other facilities should incorporate modern MPC\&A consistent with IAEA standards. As a step in this direction, and as a demonstration of transparency, Russia could request help from IAEA in planning MPC\&A measures for plutonium disposition facilities.

\section{Enhancement and Demonstration of MPC\&A}

The enhancement and demonstration of MPC\&A need not, and should not, wait until plutonium disposition decisions are made and implemented. In particular, the enhancement and demonstration of the protection of nuclear materials could be accomplished quickly at a very reasonable cost. Russian Interior Minister Viktor Yerin recently reported that $80 \%$ of Russian nuclear sites lacked basic equipment at their gates for detecting radioactive substances. ${ }^{16}$ Recently, a United States-Russian laboratory-to-laboratory effort has installed a portal radiation monitor at a facility of the Russian Institute of Physical and Power Engineering (IPPE) in Obninsk. ${ }^{17}$

14 Oleg Bukharin, Cooperation between U.S. and MINATOM in the Area of Fissile Material Safeguards, Presentation at a meeting of the President's Committee of Advisers on Science and Technology, Washington, DC, January 27, 1995.

15 Walter Y. Kato, Nuclear Material Protection, Control, and Accounting (MPC\&A) in the Russian Federation, Workshop on Plutonium Disposition sponsored by the German-American Academic Council, Bonn, March, 23 , 1995.

16 Margaret Shapiro, Russia Orders Tightened Security to Protect Nuclear Materials, The Washington Post, February 24, 1995.

17 Gennady Pshakin, Igor Matveenko (IPPE, Obninsk, Russia), Leslie Fishbone (BNL), Roger Vogel (SNL), Jack Blasy (LLNL), John Phillips (LANL), Bradley Weil (ORNL), Ken Byers (PNL), MPC\&A Lab-to-Lab Program Activities at IPPE, submitted for Institute of Nuclear Materials Management Annual Meeting, Palm Desert, July 1995. 
Installation of such monitors is also planned for some facilities at Arzamas-16, Chelyabinsk-70, and Tomsk-7. However, at these and other sites in Russia, there may be as many as 100 facilities, all together, that store or handle nuclear materials. ${ }^{18}$ The number of required portal monitors could be higher. The cost for the type of portal monitor installed at the IPPE facility is about $\$ 23,000.19$ One hundred such portal monitors would cost $\$ 2.3 \mathrm{M}$. Cost savings and increased security could be realized if the materials to be protected were consolidated at fewer facilities.

Although the cost for walk-through portal monitoring is not prohibitive, it will take some time to produce and install portal radiation monitors at all the necessary facilities. ${ }^{20}$ In the meantime, it would be possible to institute portal monitoring quickly and cheaply by using hand-held monitors. The TSA Systems PRM-470 monitor sells for about $\$ 1625,21$ and the company's affiliate has already translated the users' manual into Russian. This type of monitoring could be augmented by the use of metal detectors, especially at facilities that handle plutonium and highly enriched uranium in metal form. Metorex Inc. sells walk-through metal detectors for about $\$ 4600$ installed. 22 Thus it would cost about $\$ 6225$ to equip each portal with a hand-held radiation monitor and a walk-through metal detector, and about $\$ 622,500$ for 100 portals. The cost could be reduced to about $\$ 1825$ per portal ( $\$ 182,500$ for 100 portals) if hand-held metal detectors were used. While much faster and less expensive to initiate, a hand-held monitoring program would require the extensive use of monitoring personnel and would depend for effectiveness on the reliability on these people.

Finally, if Russia were to commit to a program to install portal monitoring at all facilities handling nuclear materials, one would expect that countries worried about

18 Nuclear Successor States of the Soviet Union. The Carnegie Endowment for International Peace and the Monterey Institute of International Studies, Number 2, December 1994.

19 The monitor sells for $\$ 20,000$ and it is estimated to cost about $\$ 3000$ to install in Russia. Allen D. Frymire, TSA Systems Ltd., Longmont, CO, personal communication (1995).

20 TSA Systems Ltd. has an affiliate, Polimaster, in Minsk that can produce portal monitors. Bob R. Miller, TSA Systems Ltd., Longmont, CO, personal communication (1995).

21 Allan D. Frymire, TSA Systems Ltd., Longmont, CO, personal communication (1995).

22 Carol Shaltis, Metorex Inc., Langhorne, PA, personal communication (1995). (Hand-held metal detectors cost about $\$ 200$.) 
the theft of nuclear materials in Russia would offer financial support. In any case, it would be important for Russia to make such a program transparent, so that the world community could have confidence that all nuclear materials in Russia are secure. This could be accomplished by allowing inspections of portal monitoring by individual countries or international groups.

\section{Summary, Conclusions, and a Recommendation}

1. MPC\&A for disposition of excess weapons plutonium is essential, and it is feasible whether the disposition option is MOX reactor fuel or immobilization and direct disposal.

2. Ensuring that all plutonium containers are accounted for and have not been tampered with is easier and more effective than verifying the precise inventory of plutonium in containers.

3. The security of immobilized plutonium depends on a number of barriers built in to the disposal system that may work together synergistically to prevent theft and reuse.

4. The decision, in Russia, between MOX use and immobilization and direct disposal will not likely be driven by MPC\&A considerations.

5. Early implementation of disposition decisions can establish a programmatic momentum toward protection of nuclear materials while conditions in the United States and Russia are favorable.

6. In Russia, a MOX option could be started sooner than an immobilization option.

7. Demonstration of MPC\&A is essential, and the use of new facilities offers an excellent opportunity to incorporate transparency.

8. The protection of nuclear materials in Russia could be enhanced and demonstrated, quickly and inexpensively, by the use of hand-held radiation monitors at nuclear facility portals. 


\section{Acknowledgments}

The author thanks colleagues at Livermore, Los Alamos, and Savannah River who provided information for this paper, and Allan D. Frymire of TSA Systems Ltd. and Carol Shaltis of Metorex Inc. for providing information on radiation and metal detectors, respectively. In addition the comments and suggestions provided by P.W. Murphy, and P. L. Chrzanowski of LLNL, D. F. Bunch of Management Strategies, Inc., and Oleg Bukharin of the Center for Energy and Environmental Studies of Princeton University are gratefully acknowledged.

Work performed under the auspices of the U.S. Department of Energy by Lawrence Livermore National Laboratory under Contract W-7405-Eng-48. 